\title{
Open Channel Structure and Ion Binding Sites of the Nicotinic Acetylcholine Receptor Channel
}

\author{
John A. Dani \\ Baylor College of Medicine, Department of Physiology and Molecular Biophysics, Houston, Texas 77030
}

\begin{abstract}
Clonal BC3H-1 muscle cells were studied using patch-clamp techniques. The structure and ion binding sites of the nicotinic ACh receptor channel were examined by measuring permeability ratios and streaming potentials. The permeability ratio of lithium to ammonium remained constant from 10 to $150 \mathrm{~mm}$. That result indicates there is one primary binding site in the narrowest region of the channel over the concentration range tested. There are, however, other binding sites and many ions in the large entrance vestibules. The sites in the wider regions of the channel influence ionic permeation, but the main determinant of transport is the site directly in the permeation pathway. An estimate of the length of the narrow region was obtained from streaming potential measurements. The streaming potential is directly related to the number of water molecules coupled to the transport of a permeant ion through the pore. Under proper experimental conditions, streaming potential measurements indicated that the narrowest cross section of the pore holds only about 6 water molecules. Therefore, the narrowest cross section is very short, and it contains one main binding site. The overall results are consistent with the pore being lined by transmembrane helices with a low charge density. Since the open pore has a short narrow region, the helices that rim the pore may spread out from the narrowest cross section. The widening of the pore would expose a second set of transmembrane helices at the interstices between the first set of helices.
\end{abstract}

Nicotinic acetylcholine receptors (AChRs) are concentrated at synapses throughout the central and peripheral nervous system. Diffusely distributed extrasynaptic receptors appear on embryonic, uninnervated, and denervated muscle cells. The AChRchannel complex mediates synaptic transmission. Upon binding $\mathrm{ACh}$, the AChRs open cation-selective channels responsible for dcpolarizing the postsynaptic cell.

The AChR channel is composed of 5 subunits, 4 of which are different, homologous polypeptides. There is general agreement that the 5 subunits are arranged like staves of a barrel around the central pore. The channel is about $14 \mathrm{~nm}$ long and has a 3-nm-wide external entrance (Brisson and Unwin, 1985). Deep-

Received Apr. 21, 1988; revised Aug. 24, 1988; acceptcd Aug. 25, 1988.

I thank Dr. C. F. Stevens for his support (NS12961) and, along with members of his Section, for providing a wonderful environment during part of this work. I thank Dr. T. Claudio for providing an early copy of her manuscript. This work was supported by National Institutes of Health Grant NS21229.

Correspondence should be addressed to John A. Dani, Baylor College of Med icine, Department of Physiology and Molecular Biophysics, One Baylor Plaza, Houston, TX 77030.

Copyright $(1989$ Society for Neuroscience $0270-6474 / 89 / 030884-092 \$ 02.00 / 0$ er in the pore the narrowest cross section is $0.65 \times 0.65 \mathrm{~nm}$ (Dwyer et al., 1980). Little else is known about the internal structure of the channel.

The narrowest portion of the channel is an important determinant of permeability. In the wide regions of the channel, ions are likely to move much as in bulk solution. In the narrow region, a permeant cation must interact with the polypeptide walls. Dipoles and charged amino acids in the narrow region could coordinate around the cation to form a binding site or energy barrier that determines selectivity and limits the transport rate. Various structural models for the channel predict different transmembrane helices line the inner, narrow portions of the pore. If amphipathic helix M5 or M7 lines the pore (FinerMoore and Stroud, 1984; Guy, 1984; Ratnam et al., 1986), then there are rings of charges that should produce a series of highaffinity binding sites. If uncharged helices line the pore (Claudio et al., 1983; Devillers-Thiery et al., 1983), then multiple binding sites in the permeation pathway are less likely.

The experiments presented here estimate the length of the narrow region and determine the number of binding sites that limit permeation. The number of binding sites directly in the permeation pathway is determined from the concentration dependence of the permeability ratio. The length of the narrow region is estimated in 2 ways. The permeability ratio measurements estimate the number of ions the narrow region can hold. Streaming potential measurements estimate the number of water molecules in the narrow region. Preliminary results of this work were presented at meetings (Dani, 1986b, 1987, 1988).

\section{The experiments}

The strongest evidence about the number of binding sites along the permeation pathway comes from the concentration dependence of the permeability ratio (see Levitt, 1986). The permeability ratio is calculated from the reversal potential under particular experimental conditions. One permeant ion is placed on one side of the membrane and the same concentration of a different permeant ion is placed on the other side. The 2 cations move in opposite directions down their concentration gradients through open AChR channels. The 1-way fluxes depend on the different permeabilities of the 2 cations. The net ionic flux is zero at the reversal potential. If the ratio remains constant as the concentration is varied, that is strong evidence there is one main binding site directly in the permeation pathway over that concentration range. Such a site would be most likely locatcd in the narrowest region of the pore where amino acid side chains could coordinate around the cation to form the binding site. Therefore, this result is indirect evidence for the number of cations within the narrow region. 
A more direct measure of the length of the narrow region is obtained by estimating the number of water molecules it can hold. Streaming potential measurements directly tell the number of water molecules coupled to the transport of a permeant cation through the channel (Levitt et al. 1978; Rosenberg and Finkelstein, 1978). The water molecules coupled to the largest cation that can fit through the pore give an estimate of the number of water molecules in the narrowest region. As the largest cation passes through, the water molecules in the narrowest cross section of the pore must be pushed out in front. The length is calculated by knowing that the narrowest cross section of the AChR channel holds 4 water molecules abreast (Dwyer et al., 1980 ) and that a water molecule is about $0.3 \mathrm{~nm}$ in diameter.

How does a streaming potential arise? Identical solutions bathe both sides of the membrane. Then, an impermeant nonelectrolyte is added to one side. The osmotic pressure gradient causes a water flux through the membrane and through open AChR channels. The water flux through the open channels drags permeant cations along, but the impermeant anions are left behind. Therefore, the water flux causes a separation of charge that produces a potential. This potential is appropriately called the streaming potential. The streaming potential is measured as the change in the reversal potential caused by adding an impermeant nonelectrolyte to one side of the membrane.

\section{Materials and Methods}

AChR channels from clonal $\mathrm{BC} 3 \mathrm{H}-1$ mouse muscle cells were studied using patch-clamp techniques.

Tissue culture. Clonal $\mathrm{BC} 3 \mathrm{H}-1$ cells were maintained using standard tcchniqucs (Sinc and Taylor, 1979; Sinc and Stcinbach, 1984). The ccll line was maintained in Dulbecco's Modified Eagle (DME) medium plus $10 \%$ heat-inactivated fetal bovine serum (10\% DME), $25 \mathrm{~mm}$ glucose, $100 \mathrm{units} / \mathrm{ml}$ penicillin, $100 \mu \mathrm{g} / \mathrm{ml}$ streptomycin, and $2 \mathrm{~mm}$ glutamine. For patch-clamp experiments the cells were passed onto glass coverslips (Sine and Steinbach, 1984). There, the cells were maintained in $0.5 \%$ DME to inhibit cell division and promote differentiation and production of AChRs. The cells were fed every other day.

For some whole-cell, patch-clamp experiments it was necessary that the cells form spheres that were only loosely attached to the cover glass. An enzyme treatment $5 \mathrm{~d}$ after plating was used to create the loosely attached spherical cells. The cells were treated for $30 \mathrm{~min}$ in DME plus $5 \mathrm{~mm}$ HEPES, $\mathrm{pH} \mathrm{7.4}$, and $1 \mathrm{mg} / \mathrm{ml}$ collagenase (Sigma, Type IA). Then, the cells were treated for 1-5 min in PBS plus $0.025 \%$ trypsin (Sigma, Type IX). When most of the cells had formed spheres and about $10 \%$ of them had floated away, the reaction was stopped by several washes with $0.5 \%$ DME. The cells were maintained as usual for $5 \mathrm{~d}$ before they were used for experiments. In some cases, 2 nm vinblastine (Sigma) was added to the $0.5 \%$ DME to ensure that the cells remained spherical.

Patch-clamp techniques. Standard patch-clamp techniques (Hamill et al., 1981; Sakmann and Neher, 1983) were applied using a List EPC-7 patch-clamp (Medical Systems Corp., Great Neck, NY). The patch pipettes were coated with Sylgard (Dow Corning Corp., Midland, MI) and polished over a hot platinum wire coated with glass (Dani and Eisenman, 1987). Outside-out membrane patches were used for the single-channel measurements. The patches were placed deeply into an inflow port (Dani and Eisenman, 1987) of the external solution, which contained 0.1-0.8 $\mu \mathrm{M}$ ACh to induce AChR channel openings. The currents were filtered at $1-2 \mathrm{kHz}$ by an 8-pole Bessel filter (LPF 902, Frequency Devices, Haverhill, MA) and sampled every $100-200 \mu \mathrm{sec}$ into a PDP $11 / 73$ computer through a 12-bit A/D converter (Indec Systems Inc., Sunnyvale, CA). For current-clamp experiments, samples were taken every $1.0 \mathrm{msec}$. The computer system also delivered stimuli through a 12-bit D/A converter.

Permeability ratio and streaming potential experiments. Both the permeability ratio and streaming potential experiments relied on an accurate measurement of the reversal potential $\left(V_{\text {rev }}\right)$. The streaming potential experiment also required a fast solution change and a quick determination of $V_{\text {rev }}$ to avoid unstirred layer artifacts (Dani and Levitt, 1981; Barry and Diamond, 1984).

Most reversal potential measurements used the whole-cell configuration to patch-clamp spherical cells less than $30 \mu \mathrm{m}$ in diameter. Because the cells were loosely attached to the cover glass, the whole cell could be lifted by the patch pipette without disturbing the seal. There was about a $10 \%$ success rate for lifting the cell after obtaining a wholecell seal. For fast solution changes, the cell was positioned next to the outflow port of a U tube (adapted from Krishtal and Pidoplichko, 1980; Fenwick et al., 1982). The U tube (PE 190) had a pressure head of the external solution applied to one end and a vacuum applied to the other end, and it had an elongated $1 \times 0.5 \mathrm{~mm}$ hole at the base of the $U$. The vacuum and pressure heads were balanced to prevent flow out of the hole. When a solenoid switch (General Valve Corp., Fairfield, NJ) blocked the vacuum, a large volume of the external solution flowed out the hole. This outflow rapidly changed the solution bathing the cell. Alternatively, the cell could be plunged into the hole in the direction of the pressure head to obtain a rapid solution change. Either method changed the external solution in about $100 \mathrm{msec}$. To visualize the balance of the vacuum and the pressure head, phenol red was added to the solution in the $\mathrm{U}$ tube.

The spherical cell was current-clamped to zero current to obtain a continuous record of the reversal potential. Constant-current pulses were applied to estimate the resistance of the membrane. The size of the constant-current pulse varied from seal to seal. In an acceptable experiment, the resistance of the whole-cell seal was greater than a gigaohm throughout the experiment, and application of $\mathrm{ACh}$ induced a detectable fall in the resistance.

To ensure an accurate measurement, $V_{\mathrm{rcr}}$ in the test solution was always bracketed by measurements in a control solution. An experiment was accepted only if the bracketing measurement gave a consistent value. Then the difference between the reversal potential in the test solution and control solution was calculated. Consistent offsets in the absolute potentials cancelled when the potential difference was calculated. With an equal concentration of a different permeant ion on each side of the membrane, the permeability ratio was calculated from the following equation: $P_{\text {ratio }}=\exp \left[\left(z F V_{\text {rev }}\right) /(R T)\right]$. The number of water molecules $(N)$ coupled to the transport of a permeant is related to the streaming potential $\left(V_{\text {str }}\right)$ and the osmotic pressure $\left(P_{\text {osm }}\right)$ by $N=\left(z F V_{\text {str }}\right) /\left(W P_{\text {osm }}\right)$, where $z, F, R$, and $T$ have their usual values and $W$ is the molar volume of water (Levitt et al., 1978; Rosenberg and Finkelstein, 1978).

As a test for artifacts, streaming potentials were measured with $\mathrm{BC} 3 \mathrm{H}-1$ cells doped with gramicidin channels. The above procedures were exactly duplicated to verify the methods. Gramicidin (ICN Pharmaceuticals Inc., Cleveland, $\mathrm{OH}$ ) was introduced into the cell membrane by the following procedure. Gramicidin powder was dissolved in methanol. A patch pipette was filled with the gramicidin-doped methanol. Then, with a separate electrolyte-filled pipette, a whole-cell seal was obtained. The cell was lifted from the cover glass as described above. The pipette filled with gramicidin was positioned just below the cell. Slight pressure applicd to that pipette caused the gramicidin/methanol solution to float up toward the cell. Gramicidin is a hydrophobic polypeptide that is insoluble in water (see Andersen, 1984). Therefore, when the methanol entered the bath solution, the methanol was diluted and gramicidin began to precipitate. If the methanol/gramicidin pipette was too far below the cell, the gramicidin would precipitate out of solution and would not enter the membrane. If the methanol/gramicidin pipette was too close to the cell, the methanol would damage the membrane and the cell would become leaky.

Gramicidin in methanol was passed near to the cell until the resistance of the cell fell from about a gigaohm to small fraction of a gigaohm During the development of this technique, the resistance of the cell was measured periodically in a Tris solution. Gramicidin is impermeable to Tris. Therefore, if the resistance change was detected in the Tris solution, then the membrane was leaky. If the resistance change was detected in a sodium solution but not in the Tris solution, then many gramicidin channels had entered the membrane. Streaming potentials were measured as usual, except no ACh was present in the external solutions.

Solutions. A wide range of solutions was used in the experiments. To prevent contamination during the formation of the seal, the concentration of the main permeant in the solution bathing the cells was the same as in the patch pipette. The osmolarities of the solutions were measured with a Wescor vapor pressure osmometer (Scimetrics, Inc.). The experiments were conducted at room temperature, $21^{\circ} \mathrm{C}$. Unless stated 


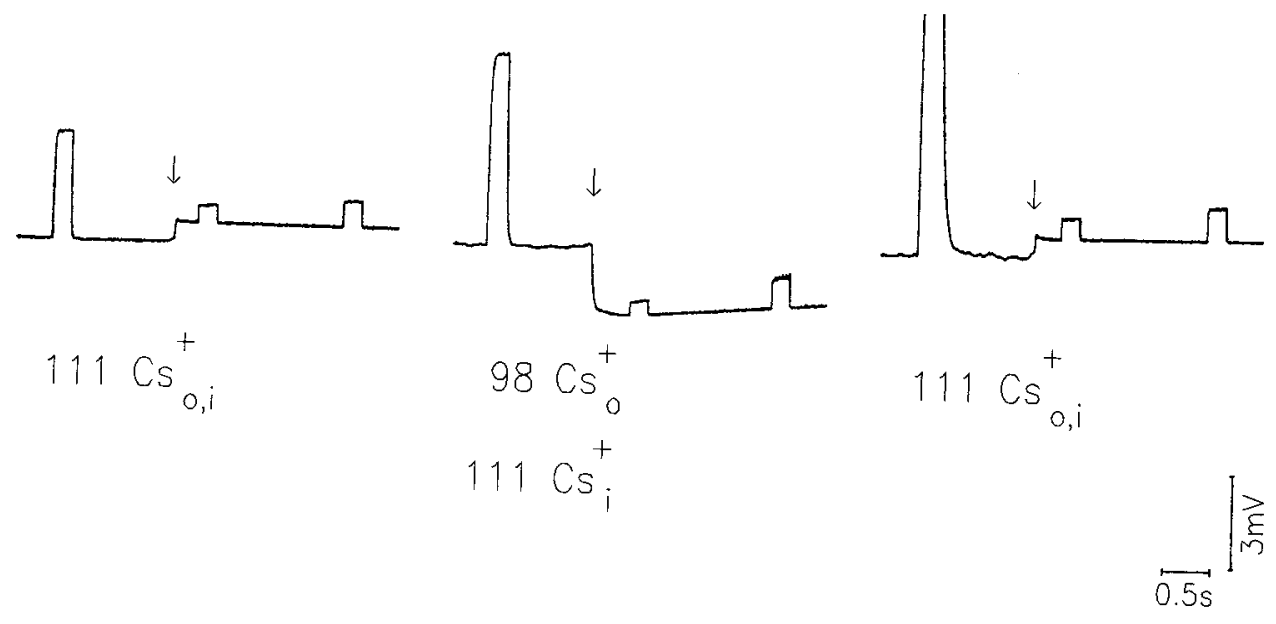

Figure 1. A Nernst potential measurement to verify the techniques. A spherical BC3H-1 cell was current-clamped to zero current to obtain a continuous reading of the reversal potential. Three constant-current pulses of $5 \mathrm{pA}$ were applied to each record. At the arrow in each record, the external solution was rapidly changed. The new external solution contained $1 \mu \mathrm{M}$ ACh, which caused AChR channels to open and the resistance of the cell to fall below a gigaohm. The middle trace is the reversal potential measurement with an activity of $98 \mathrm{mM} \mathrm{Cs}^{+}$outside and of $111 \mathrm{~mm}$ $\mathrm{Cs}^{+}$inside. This record is bracketed by controls with $111 \mathrm{mM} \mathrm{Cs}{ }^{+}$inside and outside. The difference between the reversal potentials in the 2 external solutions is $-3 \mathrm{mV}$. This observed change in the reversal potential agrees with the expected Nernst potential based on the activities of the 2 solutions. The seal improved as the experiment progressed.

otherwise, the salts were obtained from Sigma Chemical Co. and J. T. Baker Chemical Co.

The cations used in the permeability ratio experiments and the singlechannel measurements were $\mathrm{NH}_{4}{ }^{+}$and $\mathrm{Li}^{+}$. These cations were chosen because their permeabilities are different enough to produce easily measured reversal potentials (Dwyer et al., 1980). The bath was $150 \mathrm{~mm}$ $\mathrm{NH}_{4} \mathrm{Cl}$ or LiCl, $2 \mathrm{~mm} \mathrm{MgCl}, 1 \mathrm{~mm} \mathrm{CaCl}_{2}, 5 \mathrm{~mm}$ HEPES. Since low concentrations of divalent cations can influence single-channel currents of a monovalent cation (Dani and Eisenman, 1987), the external solution bathing the patch was nominally divalent free: $150 \mathrm{mM} \mathrm{NH}_{4} \mathrm{Cl}$ or LiCl, $5 \mathrm{~mm}$ HEPES with $0.1-0.8 \mu \mathrm{M}$ ACh. The pipette solution was $103 \mathrm{~mm}$ $\mathrm{NH}_{4} \mathrm{~F}$ or LiF, $25 \mathrm{~mm} \mathrm{NH}{ }_{4} \mathrm{Cl}$ or LiCl, $11 \mathrm{~mm}$ EGTA, $2 \mathrm{~mm} \mathrm{MgCl}_{2}, 1$ $\mathrm{mm} \mathrm{CaCl}_{2}, 5 \mathrm{~mm}$ HEPES. Glucose was added to the solutions to adjust their osmolarities to 0.3 osmolar. The solutions for the 10 and $50 \mathrm{~mm}$ experiments were obtained by diluting the above solutions. The osmolarities were adjusted to 0.3 osmolar with sucrose and 1 mM HEPES was added. The $\mathrm{pH}$ of these solutions was 7.3.

The streaming potential experiments had $150 \mathrm{~mm}$ triethanolammonium chloride or diethanolammonium chloride (Eastman Kodak Co.), $2 \mathrm{mM} \mathrm{MgCl}_{2}, 1 \mathrm{mM} \mathrm{BaCl}_{2}, 5 \mathrm{mM}$ HEPES in the bath and external solutions. Decreasing the divalent concentration to $1 \mathrm{mM} \mathrm{MgCl}_{2}$ and $0.5 \mathrm{BaCl}_{2}$ had no effect on the streaming potential. The internal, pipette solution was like the pipette solution described above with one of the large organic cations as the permeant species. The $\mathrm{pH}$ of these solutions was 7.0. The sodium solutions were also like those described for the single-channel experiments.
For the permeability ratio experiments, liquid junction potentials were measured between a $3 \mathrm{M} \mathrm{KCl}$ electrode and the $\mathrm{Ag} / \mathrm{AgCl}$ bath electrode using the tracking circuit of the patch-clamp. The solutions and configuration of the setup duplicated the experimental conditions. The liquid junction potentials were monitored as a function of time. Solution flow from the $U$ tube did not alter the bath enough during an experiment to change the junction potential. The liquid junction potentials maintained consistent values on repeated measurements. The values ranged up to $5 \mathrm{mV}$ in $150 \mathrm{~mm}$ electrolyte, $6 \mathrm{mV}$ in $50 \mathrm{~mm}$, and $8 \mathrm{mV}$ in $10 \mathrm{~mm}$. Liquid junction potentials did not exist for the streaming potential experiments because the electrolyte solutions in the bath and in the $U$ tube were the same.

Sucrose was used as the impermeant nonelectrolyte in the streaming potential experiments. Several of the streaming potential measurements with gramicidin used urea as the impermeant nonelectrolyte. At the concentrations used in these experiments, sucrose did not affect the activity of sodium. Ion-specific electrodes were not available for the large organic cations.

\section{Results}

The experiments required rapid solution changes and a quick, accurate determination of the reversal potential $\left(V_{\text {rev }}\right)$. Figure 1 demonstrates that small reversal potentials were quickly and accurately measured by the procedures described above. The
Figure 2. A reversal potential measurement in $150 \mathrm{~mm}$ electrolyte. The cell is current-clamped to zero current and three $20 \mathrm{pA}$, constant-current pulses indicate the resistance. The cxtcrnal solution containing $1 \mu \mathrm{M}$ ACh was applied at the arrow in each record. The middle record is the measurement with $\mathrm{Li}^{+}$outside and $\mathrm{NH}_{4}{ }^{+}$inside. Control records with $\mathrm{NH}_{4}{ }^{+}$inside and outside bracket the measurement. A liquid junction potential correction had to be added to the measurement later.
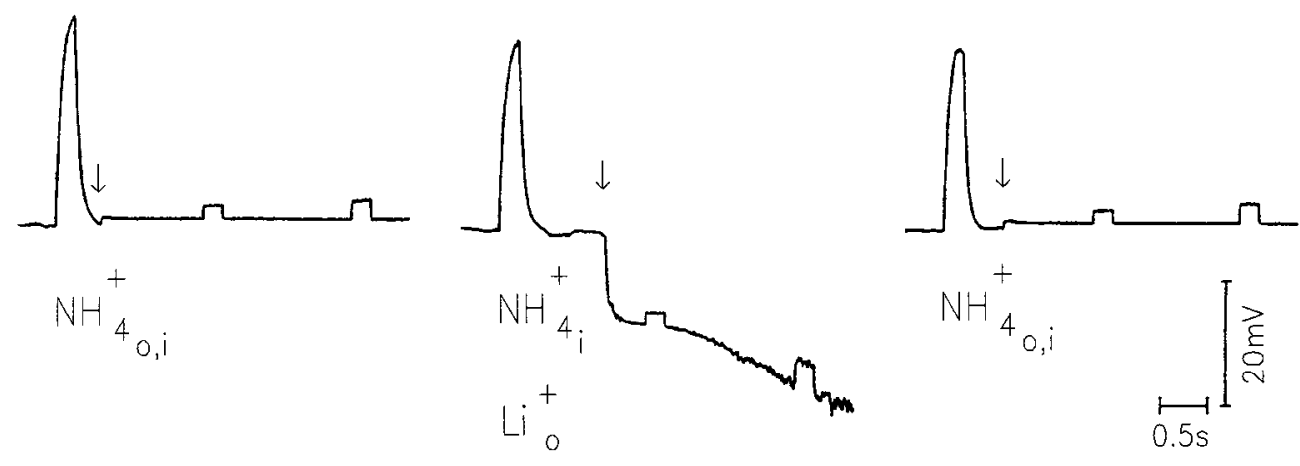

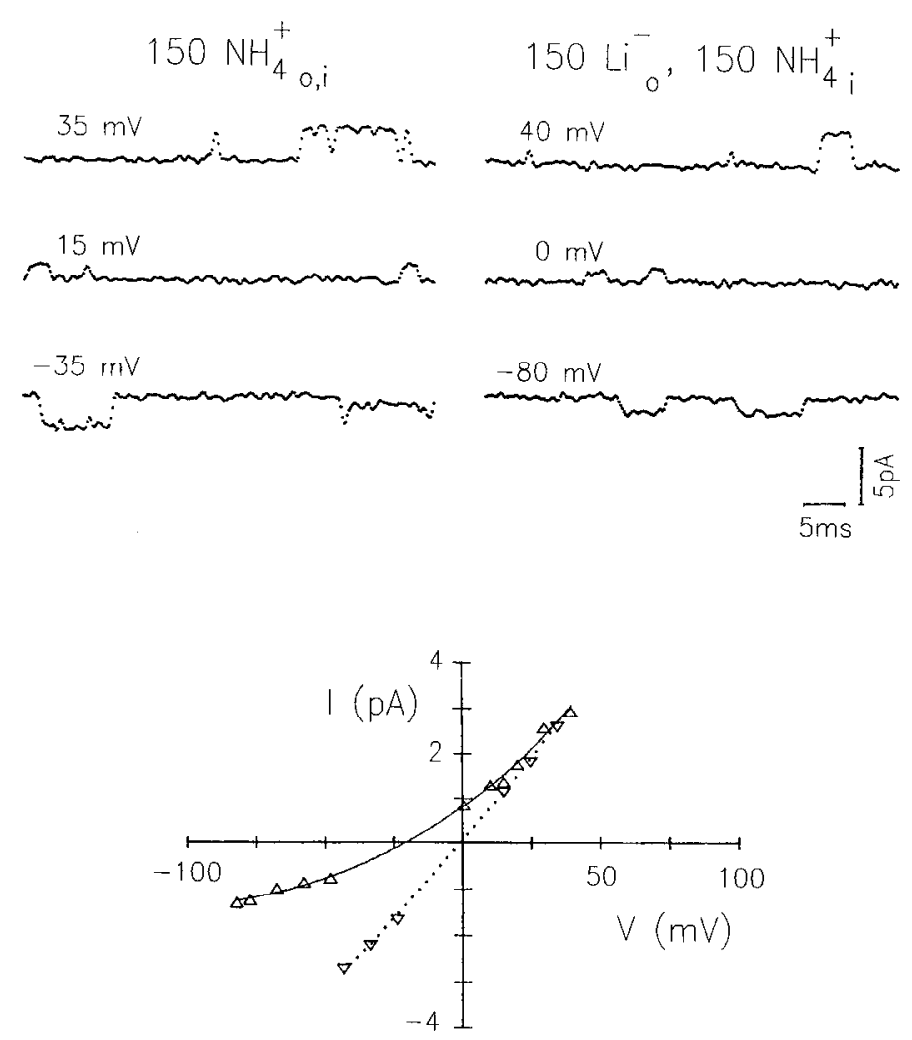

Figure 3. A reversal potential determination in $150 \mathrm{~mm}$ electrolyte. Single-channel currents at the indicated holding potentials are shown above. The reversal potential was estimated from the current-voltage relations by drawing a solid curve through the data points with $\mathrm{Li}^{+}$ outside and $\mathrm{NH}_{4}{ }^{+}$inside $(\triangle)$ and a dotted line through the controls with $\mathrm{NH}_{4}{ }^{+}$inside and outside $(\nabla)$. The SEs are smaller than the data symbols. The lines have no theoretical significance. The liquid junction potential correction has been applied to these data.

measured change in the $V_{\text {rev }}$ upon changing the external activity of the permeant cation, $\mathrm{Cs}^{+}$, was in agreement with the expected Nernst potential of $-3 \mathrm{mV}$. Thus, the solution change was complete and the reversal potential due to open AChR channels was accurately measured in about $0.1 \mathrm{sec}$.

\section{Permeability ratio measurements}

The concentration dependence of the permeability ratio of $\mathrm{Li}^{+}$ to $\mathrm{NH}_{4}{ }^{+}$was detcrmined with $\mathrm{NH}_{4}{ }^{+}$bathing the inside of the cell and $\mathrm{Li}^{+}$bathing the outside. In $150 \mathrm{~mm}$ electrolyte, the reversal potential was determined by current-clamping whole
BC3H-1 cells (Fig. 2) and by single-channel measurements (Fig. 3). The single-channel measurements confirm the current-clamp approach. In $10 \mathrm{~mm}$ electrolyte, only the whole-cell currentclamp measurement was made (Fig. 4). A summary of the results follows as $V_{\text {rev }} \mathrm{mV} \pm \mathrm{SE}(n):-21.5 \pm 0.9(6)$ in $150 \mathrm{mM},-19.5$ $\pm 2.6(4)$ in $50 \mathrm{~mm}$, and $-22.3 \pm 0.6(8)$ in $10 \mathrm{mM}$. $P_{\mathrm{L} /} / P_{\mathrm{NH}_{4}}$ is constant over this concentration range, and the ratio equals about 0.44 .

Figure 5 shows current-voltage relations with either $150 \mathrm{~mm}$ $\mathrm{Li}^{+}$or $\mathrm{NH}_{4}{ }^{+}$bathing both sides of the membrane. The conductance in $\mathrm{Li}^{+}$is $17 \mathrm{pS}$ and in $\mathrm{NH}_{4}{ }^{+}$is $79 \mathrm{pS}$. The conductance ratio is 0.22 .

\section{Streaming potential measurements}

Artifacts can develop during the streaming potential $\left(V_{\text {str }}\right)$ measurement, especially due to unstirred layers (see Levitt et al., 1978; Rosenberg and Finkelstein, 1978; Dani and Levitt, 1981). To test for artifacts, streaming potentials were measured with $\mathrm{BC} 3 \mathrm{H}-1$ cells doped with gramicidin channels. This is a critical test for problems because the streaming potential of gramicidin channels has been carefully measured in lipid bilayer membranes. Figure 6 shows a measurement of $V_{\mathrm{str}}$ when gramicidin channels were the permeation pathway in a current-clamped $\mathrm{BC} 3 \mathrm{H}-1$ cell. $V_{\text {str }}$ equaled -4.3 and $-4.5 \mathrm{mV} /$ osmolal in 2 determinations. These values agree with the streaming potential finally determined using lipid bilayers (see Levitt, 1984). In bilayer membranes or $\mathrm{BC} 3 \mathrm{H}-1$ membranes, about 9 water molecules are associated with the transport of $\mathrm{Na}^{+}$through the gramicidin channel.

Streaming potentials associated with AChR channels were determined using permeant cations triethanolammonium, diethanolammonium, or sodium. Figure 7 shows voltage-clamp records of whole $\mathrm{BC} 3 \mathrm{H}-1$ cells, indicating these cations do carry current through the AChR. When 1-[N,N-bis(2-hydroxyethyl)amino]2-propanol and triisopropanolammonium were tested, these organic cations slightly larger than triethanolammonium did not carry current.

The upper 3 current-clamp records in Figure 8 show a streaming potential measurement with the largest permeant cation, triethanolammonium. The upward deflection in a solution of the permeant plus $1 \mu \mathrm{M}$ ACh is slightly larger than in an identical solution containing 0.4 osmolal sucrose. The bottom 3 records were taken during the experiment to check for problems. Two records taken in the bath indicate that the cell and seal remained well behaved throughout the experiment. To test for movement artifacts or stretch-activated channels, the osmotic gradient was
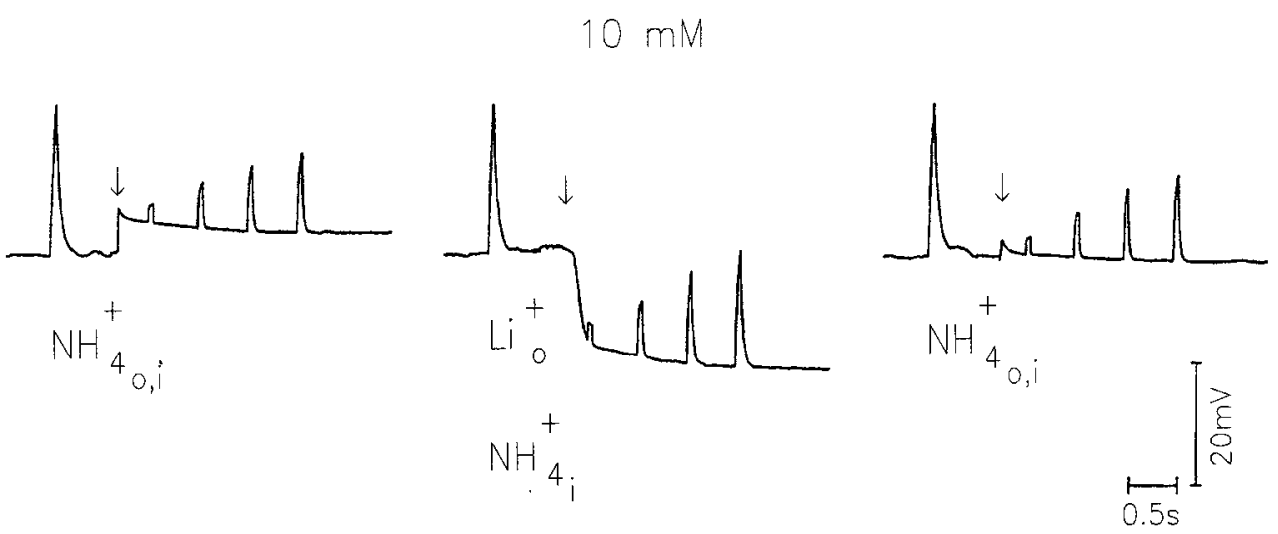

Figure 4. A reversal potential measurement in $10 \mathrm{~mm}$ electrolyte. The cell is current-clamped to zero current and five $20 \mathrm{pA}$, constant-current pulses indicate the resistance. The external solution containing $1 \mu \mathrm{M} \mathrm{ACh}$ was applied at the arrow in each record. The middle record is the measurement with $\mathrm{Li}^{+}$outside and $\mathrm{NH}_{4}{ }^{+}$inside. Control records with $\mathrm{NH}_{4}{ }^{+}$inside and outside bracket the measurement. A liquid junction potential correction had to be added to the measurement later. 

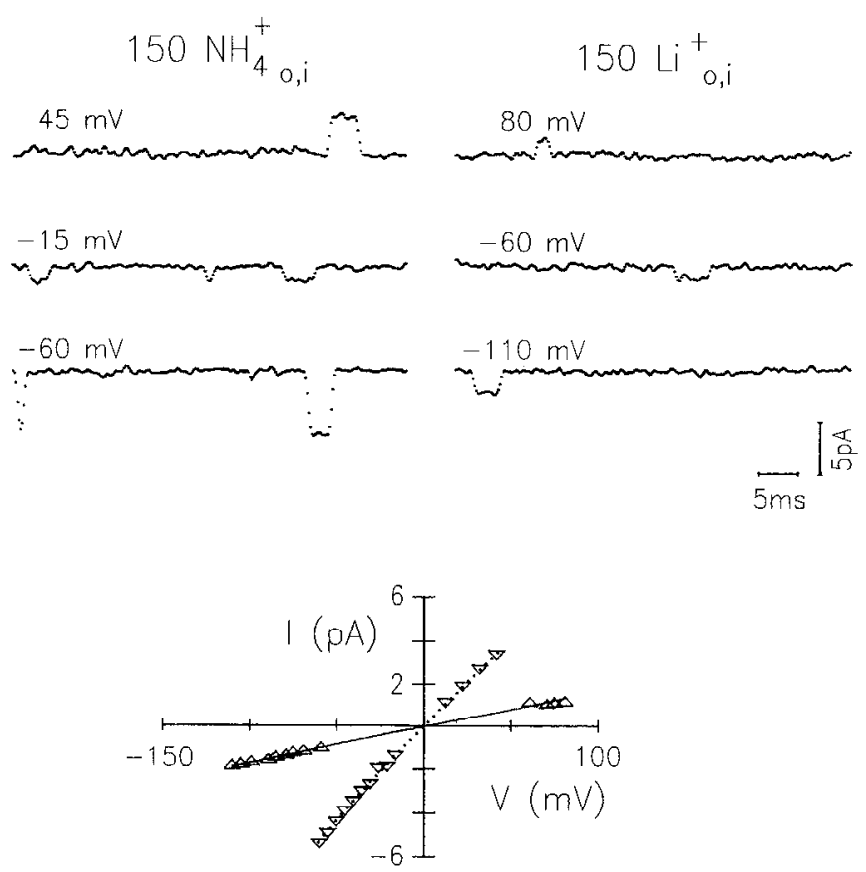

Figure 5. A single-channel conductance determination in symmetrical solutions. The permeant ion on both sides of the membrane is either $150 \mathrm{mM} \mathrm{NII}_{4}^{+}$or $\mathrm{Li}^{+}$. Single-channel currents at the indicated holding potentials are shown above. The conductance was estimated from the current-voltage relations for $\mathrm{NH}_{4}{ }^{+}(\nabla)$ and $\mathrm{Li}^{+}(\triangle)$. The SEs are smaller than the data symbols. The lines have no theoretical significance.

applied to the cell without opening AChR channels. As indicated by the bottom, middle trace, no unexpected streaming potential or other artifactual potential resulted.

Another possible problem is that a chloride permeation pathway would shunt the streaming potential. To test for this problem, chloride was replaced by the large anion, methanesulfonate.
Table 1. AChR channel streaming potentials

\begin{tabular}{llllll} 
Permeant & Anion & $\begin{array}{l}V_{\text {str }} \\
(\mathrm{mV} / \\
\text { osmolal })\end{array}$ & $\begin{array}{l}\mathrm{SE} \\
(\mathrm{mV})\end{array}$ & $\begin{array}{l}\text { Imper- } \\
\text { meant } \\
(\mathrm{M})\end{array}$ \\
\hline $\mathrm{HN}\left(\mathrm{CH}_{2} \mathrm{CH}_{2} \mathrm{OH}\right)_{3}{ }^{+}$ & $\mathrm{Cl}^{-}$ & -2.4 & 0.9 & 4 & 0.4 \\
$\mathrm{HN}\left(\mathrm{CH}_{2} \mathrm{CH}_{2} \mathrm{OH}\right)_{3}{ }^{+}$ & $\mathrm{CH}_{3} \mathrm{SO}_{3}{ }^{-}$ & -2.4 & 0.1 & 3 & 0.5 \\
$\mathrm{H}_{2} \mathrm{~N}_{\left(\mathrm{CH}_{2} \mathrm{CH}_{2} \mathrm{OH}\right)_{2}{ }^{+}}$ & $\mathrm{Cl}^{-}$ & -2.2 & 2.1 & 3 & 0.2 \\
$\mathrm{H}_{2} \mathrm{~N}_{\left(\mathrm{CH}_{2} \mathrm{CH}_{2} \mathrm{OH}\right)_{2}{ }^{+}}$ & $\mathrm{Cl}^{-}$ & -2.3 & 0.3 & 3 & 0.4 \\
$\mathrm{Na}^{+}$ & $\mathrm{Cl}^{-}$ & -0.8 & 0.4 & 3 & 0.4 \\
\hline
\end{tabular}

The impermeant nonelectrolyte for these experiments was sucrose. $V_{\text {sir }}$ is the streaming potential; $\mathrm{SE}$ is the standard error; $n$ is the number of determinations.

Figure 9 shows a streaming potential measurement with triethanolammonium as the permeant and methanesulfonate as the anion. Table 1 lists streaming potentials under all experimental conditions. The results indicate about 5-6 water molecules are coupled to the transport of the largest cation through the AChR channel.

\section{Discussion}

The lithium/ammonium permeability ratio remains constant over a concentration range from 10 to $150 \mathrm{~mm}$. This result indicates there is one main cation binding site directly in the permeation pathway. Every cation that passes through the channel must encounter this site, and the cation may encounter other sites. Since the conductance ratio does not equal the permeability ratio at $150 \mathrm{~mm}$, there is significant occupancy of the site (Decker and Levitt, 1983; see Levitt, 1986). Although the primary binding site is occupied, other binding sites directly in the permcation pathway arc not significantly occupied at this concentration. Other cationic species and higher electrolyte concentrations should be expected to reveal lower-affinity sites along the permeation pathway.

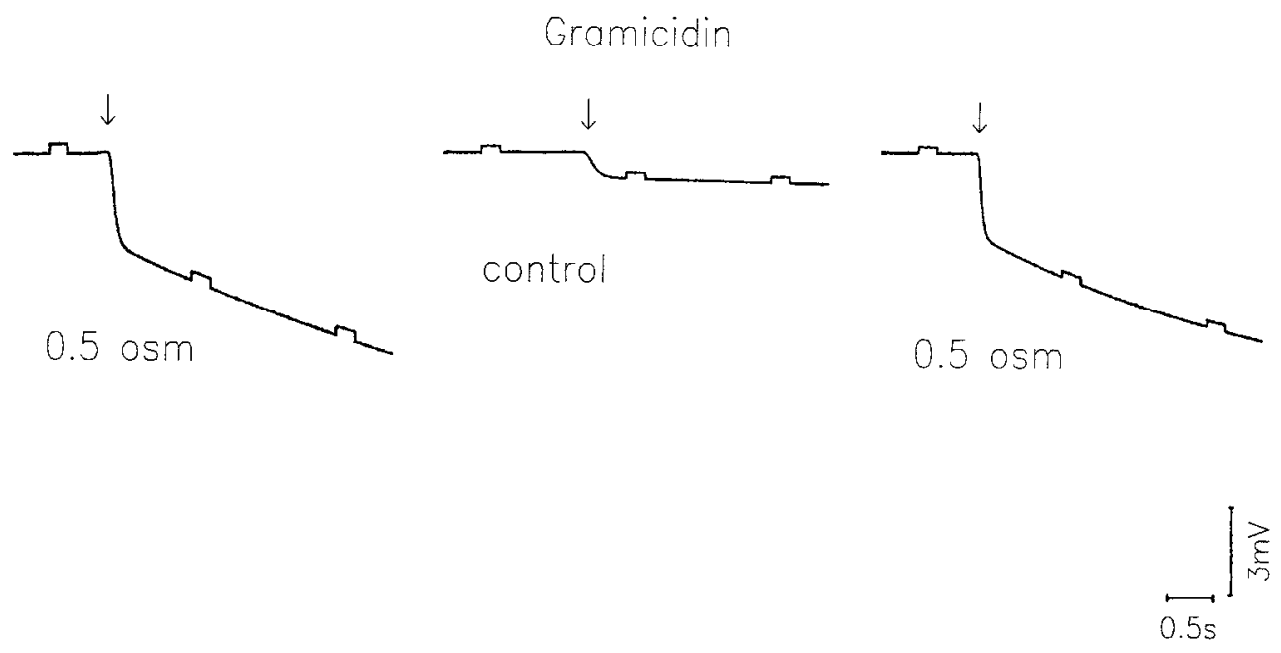

Figure 6. A streaming potential determination with gramicidin channels to verify the techniques. About 3000 gramicidin channels were introduced into the $\mathrm{BC} 3 \mathrm{H}-1$ membrane. The cell was current-clamped to zero current and three $10 \mathrm{pA}$, constant-current pulses indicate the resistance. The arrows indicate when the external solution was changed. The middle record is a control, wherc a divalent-frec sodium solution was applied. This record is bracketed by applications of the same solution containing 0.5 osmolal impermeant urea, which produced the osmotic pressure gradient. The streaming potential was taken as the difference between the control and tests at early times (about 0.1 sec). Application of an osmotic gradient to membranes containing many open gramicidin channels is expected to produce the continuous downward deflection seen in the test records. The downward deflection continues with time because the thousands of open gramicidin channels increase the water permeability of the membrane and thus exacerbate unstirred-layer problems (see Dani and Levitt, 1981). 
Sodium

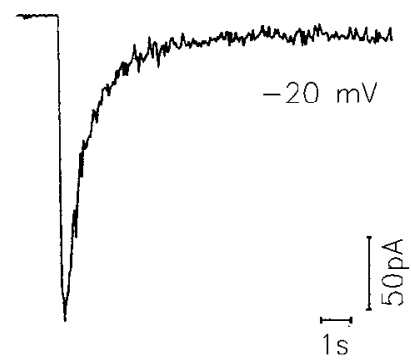

Triethanolammonium

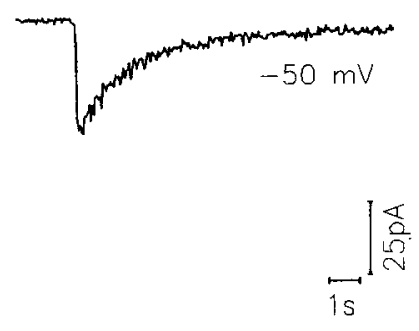

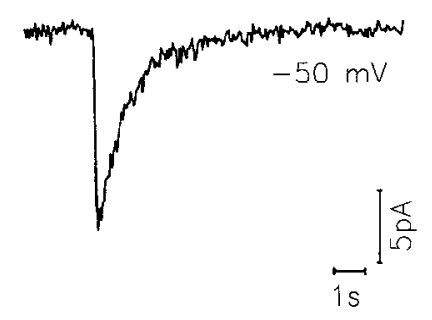

Figure 7. Whole-cell, BC3H-1 currents induced by rapid application of 1 $\mu \mathrm{M} \mathrm{ACh}$ in $150 \mathrm{mM}$ of the indicated permeant cations. The cells were voltage clamped. The holding potential and scale bars are indicated next to each record. Note that the current scale changes by a factor of 10 . Two organic cations larger than triethanolammonium did not produce measurable currents.
Streaming potentials indicate there are about 6 water molecules coupled to the transport of the largest cation. The narrowest cross section of the pore holds $4 \mathrm{H}_{2} \mathrm{O}$ abreast (Dwyer et al., 1980). Therefore, the narrowest cross section is about $0.3-0.6$ $\mathrm{nm}$ long. The result explains why there is only one main binding site that limits permeation. Only in the narrowest cross section can the protein walls coordinate around a cation to form a site that is directly in the permeation pathway. Because of electrostatic repulsion of like charges, the short narrowest region can hold only one cation at a time over the concentration range tested.

\section{Validity of the results}

Figure 1 demonstrates the main requirement for both sets of experiments. Small reversal potentials could be measured accurately. Also, the measurement was completed quickly, before unstirred layer artifacts developed (see Levitt et al., 1978). Fur- ther evidence against unstirred layer artifacts is that the streaming potential remained constant while the osmotic driving force varied (see Dani and Levitt, 1981; Barry and Diamond, 1984).

The evidence indicates that open AChR channels provided the low-resistance pathway for ion movement in these experiments. Anion channels were not a problem because potentials were the same whether chloride or methanesulfonate was the anion (Table 1). Stretch-activated channels were not a problem because application of an impermeant without ACh did not produce an artificial streaming potential (Fig. 8). Finally, triethanolammonium is too large to pass through most other channels (see Hille, 1984).

The most important experiment to confirm the results was the streaming potential measurement with gramicidin channels introduced into the BC3H-1 membrane. The measured streaming potential was in agreement with the value finally determined using lipid bilayer membranes (Levitt et al., 1978; Rosenberg
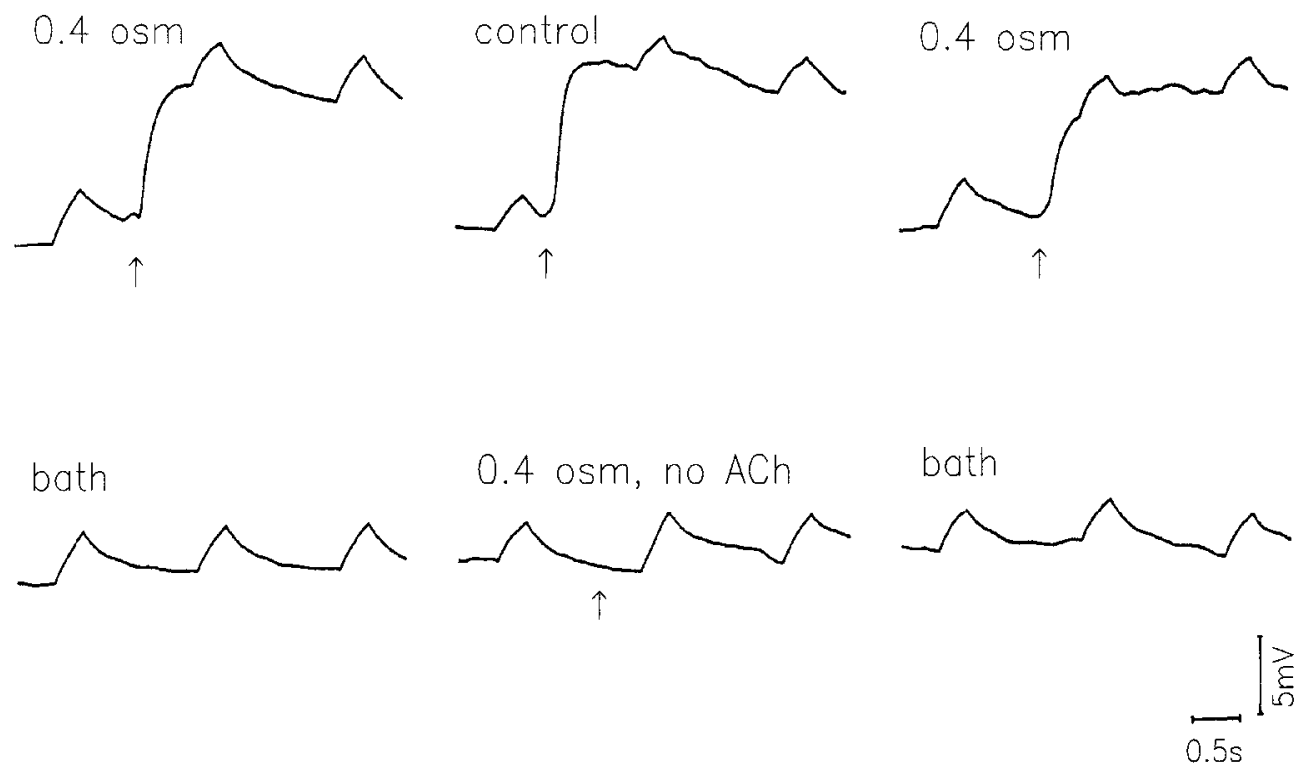

Figure 8. A streaming potential determination with triethanolammonium as the permeant cation in the AChR channels. The cell was currentclamped to zero current and three $2 \mathrm{pA}$, constant-current pulses indicate the resistance. The arrows indicate when the external solution was changed. The upper middle record is a control, where tricthanolammonium and ACh werc applicd. This record is bracketcd by applications of the samc solution containing 0.4 osmolal impermeant sucrose, which produced the osmotic pressure gradient. The upward deflection upon application of the ACh solution is largely due to the difference in activity between the internal and external solutions. The internal solution here was fluoride solution mixed with triethanolamine base and HF acid and the external solution was mixed from the chloride salt. The streaming potential was determined from the difference between the reversal potential in the control and in the solution containing sucrose. The streaming potential measured with triethanolammonium was always about $-2.4 \mathrm{mV} /$ osmolal whether or not there was a small activity difference across the membrane. The bottom records check for artifacts. The 2 records obtained in the bath indicate the resistance of the membrane remained constant and drift was small throughout the experiment. In the bottom middle record, 0.4 osmolal sucrose without ACh was applied. Although the resistance of the membrane increased slightly, no artifactual streaming potential was produced. 
Figure 9. A streaming potential determination with triethanolammonium as the permeant cation through AChR channels and with methanesulfonate as the anion. The cell was current-clamped to zero current and three $4 \mathrm{pA}$, constant-current pulses indicate the resistance. The arrows indicate when the external solution was changed. Triethanolammonium and $\mathrm{ACh}$ were applied in the 2 control records. The controls bracket application of the same solution containing 0.5 osmolal impermeant sucrose, which produced the osmotic pressure gradient. The streaming potential was taken as the difference between the controls and the test at early times (between about 0.1 and $0.5 \mathrm{sec}$ ).
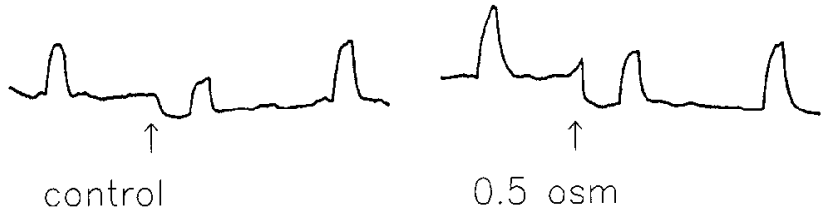

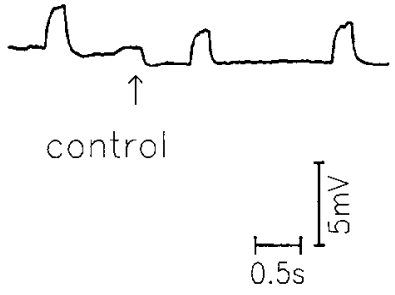

and Finkelstein, 1978; Levitt, 1984). Both measurements indicate there are about 9 water molecules in the gramicidin channel. This result indicates that the streaming potentials were measured without artifacts.

How can the result be interpreted? The streaming potential directly gives the number of water molecules coupled to the transport of a cation through the channel. To obtain structural information, it is assumed that the largest permeant ion fills the cross section at the narrowest portion of the channel. Then, the number of water molecules coupled to the largest cation is an estimate of the number of water molecules in the narrow region (see Miller, 1982).

Evidence indicates it is valid to assume water molecules in the narrow region are coupled to triethanolammonium movement through the AChR pore. Although triethanolammonium carries current, slightly larger cations are impermeable (Fig. 7; see Dwyer et al., 1980). Therefore, triethanolammonium is one of the largest permeant cations. A space-filling model of triethanolammonium completely fills a hole equivalent to the narrowest cross section determined by Dwyer et al. (1980). Space-

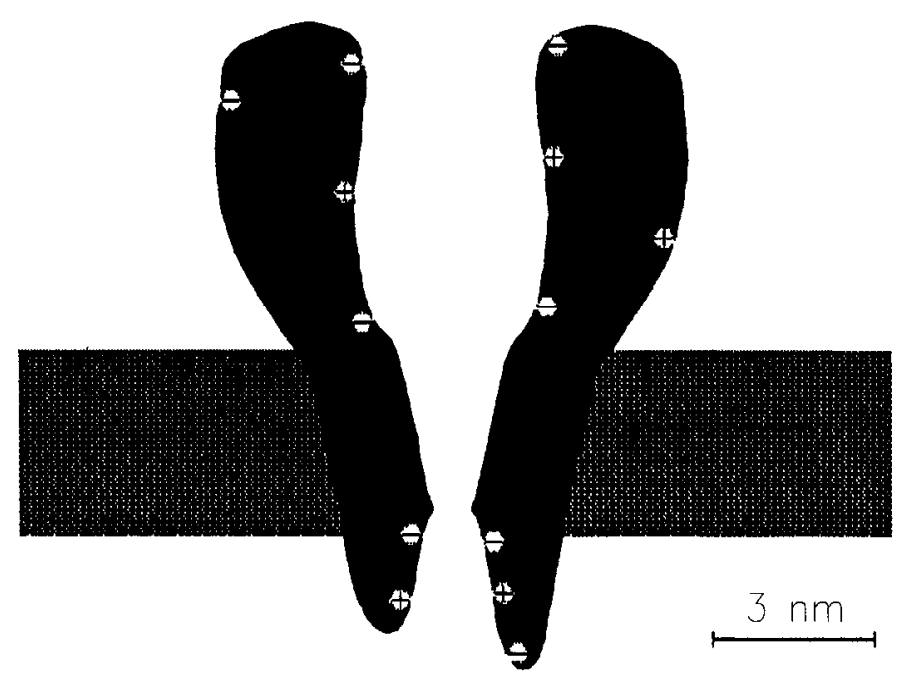

Figure 10. Schematic representation of the open nicotinic AChR channel. The membrane is lightly shaded, and the protein is more darkly shaded. Charged amino acids in the entrances and flanking the membrane spanning regions are clear circles with charges. The positions, the number, and the scale of the charged amino acids are not intended to be accurate. The transmembrane alpha-helices lining the pore are uncharged. The outside of the membrane is at the top. filling models indicate even diethanolammonium is too large to allow a water molecule to pass by it. Consistent with this finding, these 2 large cations produce the same streaming potential (Table 1). Sodium, which does not fill the narrowest cross section, produces a smaller streaming potential. That result indicates that the hydration shell of sodium must exchange many times during transport.

\section{Permeation in the AChR channel}

Most nonelectrolytes and monovalent cations that are small enough are permeable (Maeno et al., 1977; Huang et al., 1978; Dwyer et al., 1980). Small divalent cations also are permeable (Bregestovski et al., 1979; Marchais and Marty, 1979; Adams et al., 1980; Magleby and Weinstock, 1980; Takeda et al., 1982), and they have a relatively high affinity for the channel (Dani and Eisenman, 1987).

Although a single ion binding site can describe much of the permeation data, such a simple model cannot explain all the results (Lewis and Stevens, 1979; Sanchez et al., 1986; Dani and Eisenman, 1987). Studies of current-voltage relations and current blockers suggest multiple binding sites (Barry et al., 1979; Adams et al., 1981; Dani and Eisenman, 1984, 1987; Dwyer and Farley, 1984; Dwyer, 1986; Sanchez et al., 1986; for reviews, see Barry and Gage, 1984; Dani, 1988).

Especially in the wide vestibules, the AChR channel contains many ions and charged amino acids provide binding sites (Dani, 1986a; Fairclough et al., 1986). Particularly divalent cations can bind to the charged amino acids once they are attracted into the vestibule by the local negative potential (Dani, 1986a; Imoto et al., 1986; Dani and Eisenman, 1987). Unlike the site in the narrowest region, these binding sites could become saturated without limiting ion transport. In the regions where the channel is wide, cations could pass by occupied sites and carry current. Occupancy of such sites would influence permeation, but those sites might not limit ion transport or be the predominant determinants of permeability.

\section{Internal structure of the AChR channel}

Figure 10 schematically presents a structure for the AChR channel consistent with functional studies. The general shape and dimensions summarize many structural studies (Ross et al., 1977; Wise et al., 1979; Kistler et al., 1982; Brisson and Unwin, 1985; for reviews, see Guy and Hucho, 1987; Claudio, 1989). The streaming potential and permeability ratio indicate that the narrowest cross section is short and singly occupied. Theoretical 
and permeation studies suggest that the vestibules contain a net negative charge that attracts cations into the pore (Dani, 1986a; Imoto et al., 1986; Dani and Eisenman, 1987; see Eisenman and Dani, 1987).

A singlc main binding sitc dictating transport and the cncrgetics of ion transport models (Dani and Eisenman, 1987) argue against highly charged helices lining the membrane spanning region of the pore. Much evidence (see Claudio, 1989) indicates uncharged, polar, transmembrane alpha-helices provide the lining. Labeling of the channel by noncompetitive inhibitors ( $\mathrm{Gi}$ raudat et al., 1986; Hucho et al., 1986; Oberthur et al., 1986), permeation studies with delta-subunit chimeras (Imoto et al., 1986), and negative charges flanking the transmembrane helix (Dani and Eisenman, 1987) suggest that helix M2 may line the pore. Helix M1, however, is labeled by other intrachannel blockers (Karlin et al., 1986). In addition, M1 has highly conserved proline residues that suggest a channel-lining or gating role (Dani and Eisenman, 1987; Eisenman and Dani, 1987). Possibly the short narrow region reported here results because the helices that line the pore are tilted. Away from the narrowest region, the helices that line the open porc may spread out. In this wider region, a second set of transmembrane helices would then be exposed to the pore lumen. In that way, both M1 and M2 may provide lining for the open pore and could both bind intrachannel labels under different experimental conditions (see Dani, 1988).

\section{References}

Adams, D. J., T. M. Dwyer, and B. Hille (1980) The permeability of endplate channels to monovalent and divalent metal cations. J. Gen. Physiol. 75: 493-510.

Adams, D. J., W. Nonner, T. M. Dwyer, and B. Hille (1981) Block of endplate channels by permeant cations in frog skeletal muscle. J. Gen. Physiol. 78: 593-615.

Andersen, O. S. (1984) Gramicidin channels. Annu. Rev. Physiol. 46: 531-548.

Barry, P. H., and J. M. Diamond (1984) Effects of unstirred layers on membrane phenomena. Physiol. Rev. 61: 763-872.

Barry, P. H., and P. W. Gage (1984) Ionic selectivity of channels at the end plate. Curr. Top. Membr. Transp. 21: 1-51.

Barry, P. H., P. W. Gage, and D. F. Van Helden (1979) Cation permeation at the amphibian motor end-plate. J. Membr. Biol. 45: 245276.

Bregestovski, P. D., R. Miledi, and I. Parker (1979) Calcium conductance of acetylcholine-induced endplate channels. Nature 279: 638639.

Brisson, A., and P. N. T. Unwin (1985) Quaternary structure of the acetylcholine receptor. Nature 315: 474-477.

Claudio, T. (1989) Molecular genetics of acetylcholine receptor-channels. In Frontiers of Molecular Biology, Molecular Neurobiology Volume, D. Glover and D. Hames, eds., IRL, London (in press).

Claudio, T., M. Ballivet, J. Patrick, and S. Heineman (1983) Nucleotide and deduced amino acid sequences of Torpedo calfornica acetylcholine receptor subunit. Proc. Natl. Acad. Sci. USA 80: $1111-$ 1115.

Dani, J. A. (1986a) Ion-channel entrances influence permeation: Net charge, size, shape, and binding considerations. Biophys. J. 49: 607618.

Dani, J. A. (1986b) Inferred internal structure of the acetylcholine receptor pore. Soc. Neurosci. Abstr. 12: 1510.

Dani, J. A. (1987) Streaming potential measurements indicate the narrow region of the acetylcholine receptor pore is very short. Biophys. J. 51: $395 \mathrm{a}$.

Dani, J. A. (1988) Ionic permeability and the open channel structure of the nicotinic acetylcholine receptor. In Transport Through Membranes: Carriers, Channels and Pumps, A. Pullman, ed., pp. 297-319, Reidel, Dordrecht, Holland.

Dani, J. A., and G. Eisenman (1984) Acetylcholine-activated channel current-voltage relations in symmetrical $\mathrm{Na}^{+}$solutions. Biophys. $\mathrm{J}$ 45: $10-12$

Dani, J. A., and G. Eisenman (1987) Monovalent and divalent cation permeation in acetylcholine receptor channels: Ion transport related to structure. J. Gen. Physiol. 89: 959-983.

Dani, J. A., and D. G. Levitt (1981) Binding constants of Li, K, and $\mathrm{Tl}$ in the gramicidin channel determined from water permeability measurements. Biophys. J. 35: 485-500.

Decker, E. R., and D. G. Levitt (1983) Comparison of the gramicidin A potassium/sodium permeability and single channel conductance ratio. Biochim. Biophys. Acta 730: 178-180.

Devillers-Thiery, A., J. Giraudat, M. Bentaboulet, and J.-P. Changeux (1983) Complete mRNA coding sequence of the acetylcholine binding $\alpha$-subunit of Torpedo marmorata acetylcholine receptor: A model for the transmembrane organization of the polypeptide chain. Proc. Natl. Acad. Sci. USA 80: 2067-2071.

Dwyer, T. M. (1986) Guanidine block of single channel currents activated by acetylcholine. J. Gen. Physiol. 88: 635-650.

Dwyer, T. M., and J. M. Farley (1984) Permeability properties of chick myotube acetylcholine-activated channels. Biophys. J. 45: 529539

Dwyer, T. M., D. J. Adams, and B. Hille (1980) The permeability of the endplate channel to organic cations in frog muscle. J. Gen. Physiol. 75: 469-492.

Eisenman, G., and J. A. Dani (1987) An introduction to molecular architecture and permeability of ionic channels. Annu. Rev. Biophys. Biophys. Chem. 16: 205-226.

Fairclough, R. H., R. C. Miake-Lye, R. M. Stroud, K. O. Hodgson, and S. Doniach (1986) Location of terbium binding sites on acetylcholine receptor-enriched membranes. J. Mol. Biol. 189: 673-680.

Fenwick, E. M., A. Marty, and E. Neher (1982) A patch-clamp study of bovine chromaffin cells and of their sensitivity to acetylcholine. $\mathbf{J}$. Physiol. (Lond.) 331: 577-597.

Finer-Moore, J., and R. M. Stroud (1984) Amphipathic analysis and possible formation of the ion channel in an acetylcholine receptor. Proc. Natl. Acad. Sci. USA 81: 155-159.

Giraudat, J., M. Dennis, T. Heidmann, J.-Y. Chang, and J.-P. Changeux (1986) Structure of the high-affinity binding site for noncompetitive blockers of the acetylcholine receptor: Serine-262 of the delta subunit is labeled by $\left[{ }^{3} \mathrm{H}\right]$ chlorpromazine. Proc. Natl. Acad. Sci. USA 83: 2719-2723.

Guy, H. R. (1984) A structural model of the acetylcholine receptor channel based on partition energy and helix packing calculations. Biophys. J. 45: 249-261.

Guy, H. R., and F. Hucho (1987) The ion channel of the nicotinic acetylcholine receptor. Trends Neurosci. 10: 318-321.

Hamill, O. P., A. Marty, E. Neher, B. Sakmann, and F. J. Sigworth (1981) Improved patch-clamp techniques for high-resolution current recordings from cells and cell-free membrane patches. Pfluegers Arch. 391: 85-100.

Hille, B. (1984) Ionic Channels in Excitable Membranes, Sinauer, Sunderland, MA.

Huang, L. M., W. A. Catterall, and G. Ehrenstein (1978) Selectivity of cations and nonelectrolytes for acetylcholine-activated channels in cultured muscle cells. J. Gen. Physiol. 71: 397-410.

Hucho, F., W. Oberthur, and F. Lottspeich (1986) The ion channel of the nicotinic acetylcholine receptor is formed by the homologous helices MII of the receptor subunits. FEBS Lett. 205: 137-142.

Imoto, K., C. Methfessel, B. Sakmann, M. Mishina, Y. Mori, T. Konno, K. Fukuda, M. Kurasaki, H. Bujo, Y. Fujita, and S. Numa (1986) Location of the $\delta$-subunit region determining ion transport through the acetylcholine receptor channel. Nature 324: 670-674.

Karlin, A., P. N. Kao, and M. Dipaola (1986) Molecular pharmacology of the nicotinic acetylcholine receptor. Trends Pharmacol. Sci. 7: 304308.

Kistler, J., R. M. Stroud, M. W. Klymkowsky, R. A. Lalancette, and R. H. Fairclough (1982) Structure and function of an acetylcholine receptor. Biophys. J. 37: 371-383.

Krishtal, O. A., and V. I. Pidoplichko (1980) A receptor for protons in the nerve cell membrane. Neuroscience 5: 2325-2327.

Levitt, D. G. (1984) Kinetics of movement in narrow channels. Curr. Top. Membr. Transp. 21: 181-197.

Levitt, D. G. (1986) Interpretation of biological ion channel flux data: Reaction-rate versus continuum theory. Annu. Rev. Biophys. Biophys. Chem. 15: 29-57. 
Levitt, D. G., S. R. Ellias, and J. M. Hautman (1978) Number of water molecules coupled to the transport of sodium, potassium and hydrogen ions via gramicidin, nonactin or valinomycin. Biochim. Biophys. Acta 512: 436-451.

Lewis, C. A., and C. F. Stevens (1979) Mechanism of ion permeation through channels in a postsynaptic membrane. In Membrane Transport Processes, Vol. 3, C. F. Stevens and R. W. Tsien, eds., pp. 89103, Raven, New York.

Maeno, T., C. Edwards, and M. Anraku (1977) Permeability of the end-plate membrane activated by acetylcholine to some organic cations. J. Neurobiol. 8: 173-184.

Magleby, K. L., and M. M. Weinstock (1980) Nickel and calcium ions modify the characteristics of the acetylcholine receptor-channel complex at the frog neuromuscular junction. I. Physiol. (Lond.) 299: 203218.

Marchais, D., and A. Marty (1979) Interaction of permeant ions with channels activated by acetylcholine in Aplysia neurons. J. Physiol. (Lond.) 297: 9-45.

Miller, C. (1982) Coupling of water and ion fluxes in a K-selective channel of sarcoplasmic reticulum. Biophys. J. 38: 227-230.

Oberthur, W., P. Muhn, H. Baumann, F. Lottspeich, B. WittmannLiebold, and F. Hucho (1986) The reaction site of a non-competitive antagonist in the delta subunit of the nicotinic acetylcholine receptor. EMBO J. 5: 1815-1819.

Ratnam, M., D. Le Nguyen, J. Rivier, P. B. Sargent, and J. Lindstrom
(1986) Transmembrane topography of nicotinic acetylcholine receptor: Immunochemical tests contradict theoretical predictions based on hydrophobicity profiles. Biochemistry $25: 2633-2643$.

Rosenberg, P. A., and A. Finkelstein (1978) Interaction of ions and water in gramicidin A channels: Streaming potentials across lipid bilaycr membrancs. J. Gcn. Physiol. 72: 327-340.

Ross, M. J., M. W. Klymdowsky, D. A. Agard, and R. M Stroud (1977) Structural studies of a membrane-bound acetylcholine receptor from T. californica. J. Mol. Biol. 116: 635-659.

Sakmann, B., and E. Neher, eds. (1983) Single-Channel Recording, Plenum, New York.

Sanchez, J. A., J. A. Dani, D. Siemen, and B. Hille (1986) Slow permeation of organic cations in acetylcholine receptor channels. J. Gen. Physiol. 87: 985-1001.

Sine, S. M., and J. R. Steinbach (1984) Activation of a nicotinic acetylcholine receptor. Biophys. J. 45: 175-185.

Sine, S. M., and P. Taylor (1979) Functional consequences of agonistmediated state transitions in the cholinergic receptor. Studies on cultured muscle cells. J. Biol. Chem. 254: 3315-3325.

Takcda, K., P. W. Gage, and P. H. Barry (1982) Effects of divalent cations on toad end-plate channels. J. Membr. Biol. 64: 55-66.

Wise, D., A. Karlin, and B. P. Schoenborn (1979) Analysis by lowangle neutron scattering of the structure of the acetylcholine receptor from Torpedo californica in detergent solution. Biophys. J. 28: 473496. 